\title{
MIF production of lymphocytes from patients with rheumatoid arthritis with antigen-antibody complexes
}

\author{
MARTHA M. EIBL AND CHRISTINE SITKO \\ From the Institute of Immunology, University of Vienna, 1090 Vienna, Austria
}

\begin{abstract}
Eibl, M. M., and Sitko, C. (1975). Annals of the Rheumatic Diseases, 34, 117. MIF production of lymphocytes from patients with rheumatoid arthritis with antigen-antibody complexes. Immune complexes, human erythrocytes coated with human IgG antibody, inhibit the migration of lymphocytes from rheumatoid arthritis (RA) patients. No correlation could be observed between migration inhibition and Waaler-Rose titre (sheep cell agglutination titre) in individual patients. Production of migration inhibitory factor (MIF) could be detected in 16 of 20 cultures of RA lymphocytes incubated with antigen-antibody complexes, when the supernates were tested with guinea pig macrophages. Only two supernates of healthy persons showed migration inhibition activity under these conditions. The results suggest that migration inhibition by antigen antibody complexes in RA represents a true reaction of delayed hypersensitivity.
\end{abstract}

Lymphocytes of patients with rheumatoid arthritis (RA) react with aggregated homologous IgG as shown by us (Eibl, 1971) and others (Fröland and Gaarder, 1971; Brostoff, Howell, and Roitt, 1973), as well as with antigen-antibody complexes (Eibl, 1972). Isolated mononuclear cells show migration inhibition when tested with autologous or homologous gammaglobulin as antigen (Eibl, 1972). The same phenomenon has been shown with buffy coat cells by Fröland and Gaarder and was recently repeated by Brostoff $e t$ al. (1973). Migration inhibition could also be observed using blood group $\mathrm{O}$ D-positive erythrocytes and human IgG anti-D, as well as complexes consisting of measles antigen and human IgG antibody in slight antibody excess (Eibl, 1972). Additional indication for the reaction of RA lymphocytes with antigen-antibody complexes has been provided by Bach, Delrieu, and Delbarre (1970) who showed rosette formation of sheep erythrocytes coated with rabbit IgG antibody with lymphocytes of RA patients. We were able to show a similar reaction in a homologous system (Eibl, Sitko, and Thumb, 1973).

As for the migration inhibition observed by aggregated gammaglobulin and antigen-antibody complexes with cells of RA patients, the question arises whether this phenomenon is due to a T-cell effect or is caused by bridging, whereby the antigens react with an antiglobulin site on the surface of lymphocytes producing rheumatoid factors and would cause inhibition by cross-linking the cells. The experiments reported here were designed to analyse whether the lymphocytes of RA patients, showing migration inhibition by antigen-antibody complexes, can be stimulated in culture to produce migration inhibitory factor (MIF) by similar antigenantibody complexes under experimental conditions where stimulation of cells derived from healthy persons do not occur.

\section{Patients, materials, methods}

Twenty patients with established RA were studied. Diagnosis was made according to the criteria of Ropes, Bennett, Cobb, Jacox, and Jesser (1959). Fourteen of the patients tested had recently been referred to hospital because of active disease. Six were outpatients with quiescent disease. The age of the patients, two males and eighteen females, varied between 40 and 71 yrs with an average age of 57 . Steroid therapy did not exceed $10 \mathrm{mg}$ prednisone per day. Twenty healthy blood donors, not matched for age and sex, served as controls. The age of the controls, ten males and ten females, ranged from 23 to 52 years with an average age of 44 years.

\section{LYMPHOCYTES}

Mononuclear cells were isolated from heparinized whole blood by a modification of the method described by Thorsby and Bratlie (1970) and used by Aiuti, Lacava, Garofalo, D'Amelio, and D'Asero (1973).

$40 \mathrm{ml}$ of venous blood were collected with phenol-free heparin. $4 \mathrm{ml}$ per tube was layered gently over $2 \mathrm{ml}$ of a solution composed of $4 \cdot 78 \mathrm{~g}$ Ficoll (Pharmacia), $10 \mathrm{ml}$ 
Ronpacon (Cilag-Chemie), and $65.2 \mathrm{ml}$ aqua bidest. The tubes were centrifuged at $600 \mathrm{~g}$ for $5 \mathrm{~min}$. The leucocyterich layer was aspirated, washed in TCM 199, containing $2 \%$ human albumin and adjusted to contain $5 \times 10^{6}$ cells per $\mathrm{ml}$. The isolated cell suspension contained approximately $90-95 \%$ mononuclear cells, of which $6-10 \%$ were monocytes as judged by latex phagocytosis.

\section{ERYTHROCYTES}

Human D-positive erythrocytes of blood group $\mathrm{O}$ were used.

\section{ANTI-D ANTIBODIES}

An anti-D IgG preparation with an antiglobulin titre of $1: 2000$ was used in a dilution $1: 100$ to sensitize erythrocytes.

\section{ANTIGEN-ANTIBODY COMPLEXES}

Sensitization of erythrocytes for MI in the direct assay The IgG preparation with an anti-D titre of $1: 2000$ was diluted 1:100. To $2 \mathrm{ml}$ of $1 \%$ suspension of D-positive erythrocytes $2 \mathrm{ml}$ of the diluted antibody were added, and red cells were sensitized for 1 hour at $37^{\circ} \mathrm{C}$. Sensitized cells were washed twice and resuspended in MEM to contain $5 \times 10^{8}$ cells per ml. To each tube of $5 \times 10^{6}$ lymphocytes $0 \cdot 1 \mathrm{ml}$ sensitized erythrocytes were added.

\section{Sensitization of erythrocytes used for stimulation of MIF production}

$20 \mathrm{ml}$ of a $5 \%$ suspension of human erythrocytes (Dpositive) were incubated for one hour at $37^{\circ} \mathrm{C}$ with $4 \mathrm{ml}$ of undiluted anti-D antibody. Erythrocytes were washed twice after sensitization and resuspended in $2 \mathrm{ml}$ MEM. To each lymphocyte culture $0.2 \mathrm{ml}$ of sensitized erythrocytes were added.

MIGRATION INHIBITION OF MONONUCLEAR CELLS The method of Falk, Thorsby, Möller, and Möller (1970) was slightly modified. $5 \times 10^{6}$ mononuclear cells and $5 \times 10^{7}$ sensitized erythrocytes were incubated for $1 \frac{1}{2}$ hours at $37^{\circ} \mathrm{C}$. Nonsensitized erythrocytes were added to the controls. After incubation, the cell mixture was centrifuged at $500 \mathrm{~g}$ for $5 \mathrm{~min}$. The pellet was resuspended in the minimum possible amount of medium and the packed cells were filled in siliconized capillary tubes $1 \mathrm{~mm}$ in width, heat-sealed on one side. The capillaries were centrifuged at $500 \mathrm{~g}$ for $5 \mathrm{~min}$, cut just below the cell fluid interphase, and fixed with sterile silicone grease on the bottom of a Syke-Moore tissue culture chamber. Chambers were filled with MEM containing Pen. Strep. and $10 \%$ fetal calf serum. The migration took place at $37^{\circ} \mathrm{C}$ for $24 \mathrm{~h}$. Migration areas were magnified by standard technique, cut out of pergament, and weighed on a precision balance. Migration indices have been calculated in the following manner:

\section{Migration index :}

\section{Migration area with sensitized erythrocytes} $\overline{\text { Migration area with nonsensitized erythrocytes. }}$

\section{MIF PRODUCTION}

Lymphocytes isolated by the Ficoll-isopaque technique were used. A suspension of $2 \times 10^{7}$ lymphocytes $/ \mathrm{ml}$ was prepared in MEM with Pen. Strep. and 5\% human serum albumin added. $1.5 \mathrm{ml}$ of lymphocytes were placed in a Leighton type tube (with bottom of $1.5 \mathrm{~cm}^{2}$ ) $.0 .2 \mathrm{ml}$ of sensitized erythrocytes were added to the experimental tubes while the same amount of nonsensitized erythrocytes was added to the controls. Final volume in every tube was $1.7 \mathrm{ml}$. The tubes were incubated for 24 hours at $37^{\circ} \mathrm{C}$ in a $\mathrm{CO}_{2}$ incubator. After $24 \mathrm{~h}$. the tubes were centrifuged for $3 \mathrm{~min}$ at $2500 \mathrm{~g}$. The supernates $(1.2 \mathrm{ml}$ each) were collected in individual tubes and tested on guinea pig macrophages for migration inhibitory activity. Controls were treated the same way, set up and tested on the same day. At least one patient and one control were tested with any one guinea pig macrophage suspension and also MIF was obtained in duplicate experiments and tested on two different macrophage preparations.

MIF TESTING

Peritoneal macrophages of guinea pigs were obtained 5 days after injection of $5 \mathrm{ml}$ sterile paraffin oil into the peritoneal cavity of healthy outbred guinea pigs. The peritoneal cavity was rinsed with TCM 199 containing Pen. Strep. heparin and $2 \%$ human serum albumin. $5 \times 10^{6}$ macrophages were added to $0.5 \mathrm{ml}$ MIF containing supernates and $0 \cdot 1 \mathrm{ml}$ fetal calf serum. After an incubation time of $90 \mathrm{~min}$ at $37^{\circ} \mathrm{C}$ the cells were centrifuged at $500 \mathrm{~g}$ for $5 \mathrm{~min}$. The pellet was resuspended, put into siliconized capillary tubes, centrifuged at $500 \mathrm{~g}$ for 5 min, and cut at the cell fluid interphase. Two capillaries were fixed with silicone grease at the bottom of a SykeMoore tissue culture chamber. The chamber was filled with MEM, supplemented by $20 \%$ fetal serum. $0.5 \mathrm{ml}$ MIF containing supernates were added to every chamber. Incubation was carried out for $24 \mathrm{~h}$. Migration areas were magnified and weighed. The effect of MIF was calculated as follows:

\section{Migration index:}

Migration areas of PGM with supernates of cultures with $\mathrm{Ag}-\mathrm{Ab}-\mathrm{C}$

Migration area of PGM with supernates of cultures with Ag.

Waaler rose titres were measured as described by Steffen (1968).

\section{Results}

MIGRATION OF MONONUCLEAR CELLS FROM RA PATIENTS AND HEALTHY PERSONS IN THE PRESENCE OF ANTIGEN-ANTIBODY COMPLEXES With a cell ratio of $5 \times 10^{7}$ sensitized erythrocytes to $5 \times 10^{6}$ lymphocytes significant migration inhibition could be shown in eighteen of the RA patients tested. Results are shown in the Table. Migration indices have been calculated as described above in Methods using the migration of lymphocytes in the presence of nonsensitized erythrocytes as controls. Migration indices below 0.8 were considered to represent significant inhibition. Mean value of migration indices was 0.45 with a standard deviation of 0.23 , when lymphocytes of RA patients were 
Table Migration of $R A$ and control lymphocytes in the presence of antigen-antibody complexes (D-pos. erythrocytes coated with anti $D$ )

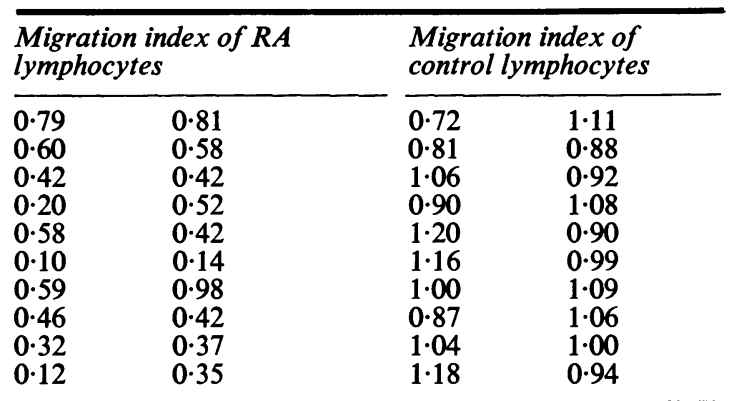

Mean migration index of the RA patients 0.45 ; standard deviation $0 \cdot 23$. Mean migration index of the controls 0.99 ; standard deviation $0 \cdot 13$. The difference between the RA and control experiments is highly significant $(\mathrm{P} \ll 0.001)$.

investigated. Only two of the eighteen positive RA patients showed moderate inhibition of lymphocyte migration by antigen-antibody complexes with a migration index of between 0.6 and 0.8 . In 16 cases there was a marked inhibition with migration indices between $0 \cdot 1$ and $0 \cdot 6$.

Lymphocytes of healthy persons did not show migration inhibition by antigen-antibody complexes in 19 of the 20 cases tested. Only one of the control lymphocytes showed moderate migration inhibition with a migration index of $\mathbf{0 . 7 2}$. Migration indices of the 19 control preparations varied between 0.81 and 1.2 , with a mean value of 0.99 and a standard deviation of $0 \cdot 127$.

The differences of standard deviation in patients and controls gave significant results in comparison of variances by means of an $F$ test $(P<0.01)$. For this reason the significance of the difference of migration indices between the RA and control groups had to be calculated by the test for different variances introduced by Welch with approximate T-value (Sachs, 1969). The difference of migration indices between controls and RA patients was highly significant $(P \ll 0.001)$.

Results of Waaler-Rose tests and migration inhibition were correlated. No correlation could be observed between these two results (Fig. 1). Two patients showing no migration inhibition had sheep cell agglutinin titres of $1: 512$ and $1: 128$, respectively. Four of the patients tested had seronegative RA; migration indices in these patients were $0.79,0.60$, $0 \cdot 42$, and $0 \cdot 20$. On the other hand, four patients having Waaler-Rose titres of $1: 512$ and above showed migration indices of $0.98,0.42,0.42$, and 0.37 .

To test MIF production of lymphocytes in the presence of antigen-antibody complexes, we used a system whereby either nonsensitized erythrocytes or sensitized erythrocytes were added to lymphocytes, and supernates of these cultures were investigated. In experimental cultures, the erythrocytes added in the same quantity have been previously sensitized with anti-D antibody. Supernates of such cultures will be described as MIF-containing supernates.

Since we were interested in studying the effect of antigen-antibody complexes, we wanted to have as few factors as possible influencing the test system. For this reason, we chose lymphocytes incubated with erythrocytes alone as the most suitable controls. Supernates of these cultures are referred to as control supernates. Migration indices have been calculated

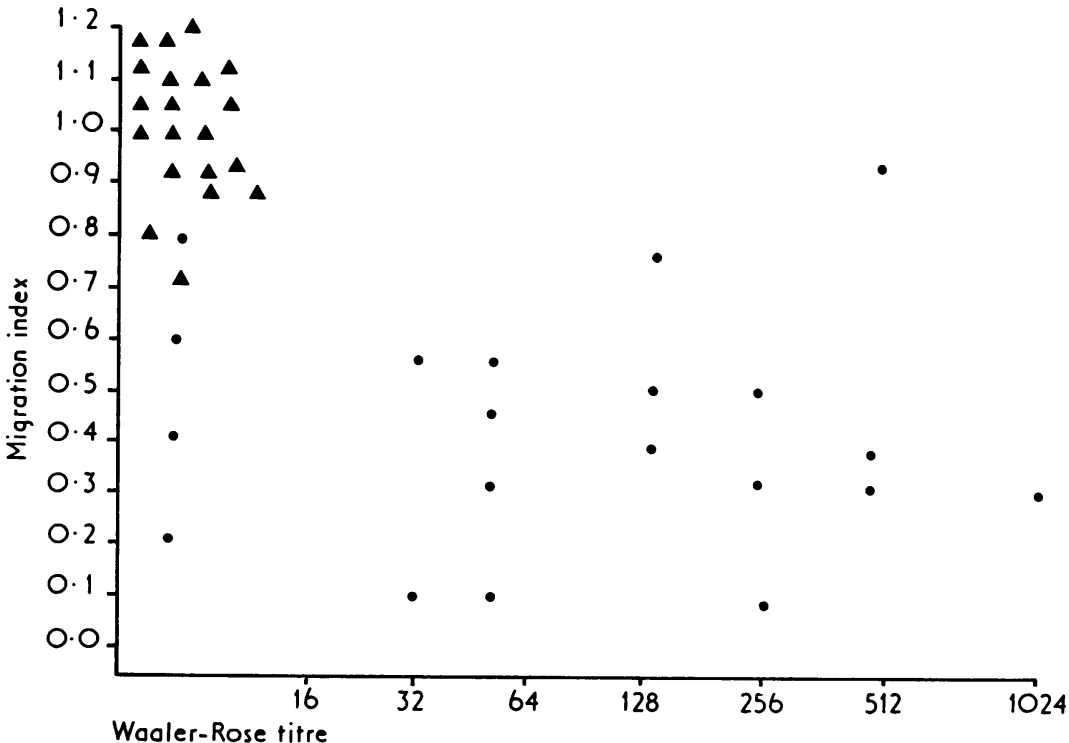

FIG. 1 Migration index of $R A$ patients and controls with antibody-coated erythrocytes. No correlation could be found between WaalerRose titre and the extent of migration inhibition. $\Delta$ controls, $\bullet R A$ patients 
by comparing the migration of guinea pig macrophages in the presence of MIF-containing supernates to migration of the same cells with control supernates. Results are shown in Fig. 2. Each point represents means of duplicate experiments. Supernates of control and experimental cultures were always tested in parallel and at least one RA patient and one control were tested on any individual guinea pig macrophage preparation. Supernates of lymphocytes of RA patients showed migration inhibitory activity in 16 of the 20 cases tested. From the 4 supernates not showing such activity, 2 were from patients who also failed to be inhibited by antigenantibody complexes in the direct migration assay.

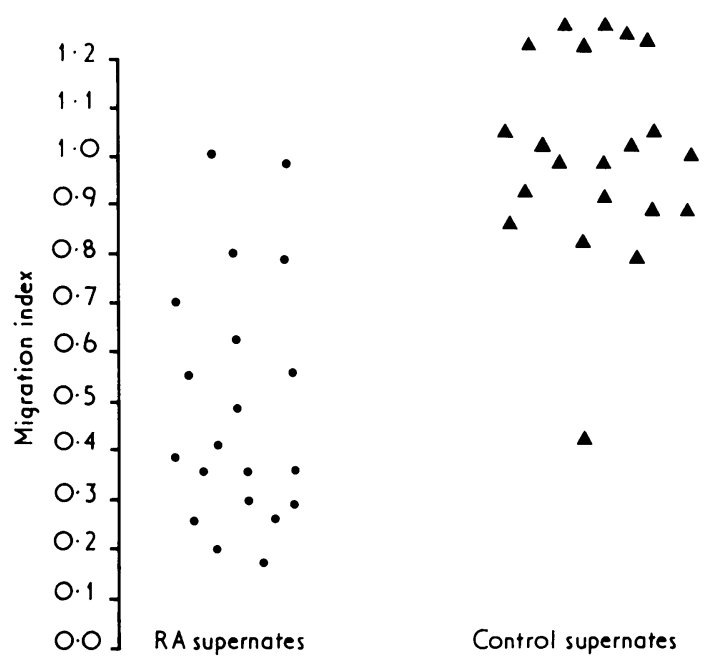

FIG. 2 Migration index of guinea pig peritoneal macrophages with supernates of $R A$ and control lymphocyte cultures. Lymphocytes have been cultured for 24 hours with antigen-antibody complexes. MIF has been shown in 16 of 20 RA supernates. Only 2 of the control supernates had significant MIF activity

The other 2 were supernates from patients whose cells did not show migration inhibition in the direct assay with indices of 0.6 and 0.52 , respectively. The mean value of migration indices with RA supernates was 0.51 with a standard error of 0.245 .

Two of the supernates of lymphocyte cultures from healthy persons caused in one case moderate, and in one case marked, migration inhibition with values of 0.77 and 0.44 . Eighteen of the supernates from control persons did not lead to migration inhibition when tested on guinea pig macrophages. The mean value of migration indices with control supernates was 0.98 with a standard deviation of $0 \cdot 268$.

The significance of the results has been checked with the T-test for independent samples with equal variances. The difference between migration indices obtained by RA supernates and control supernates is highly significant $(P \ll 0 \cdot 001)$.

\section{Discussion}

As in our earlier work (Eibl, 1972), it could be shown in this study as well that antigen-antibody complexes inhibit the migration of lymphocytes from RA patients. Lymphocytes of eighteen of twenty patients tested showed significant migration inhibition with IgG-coated red cells. The migration index was below $0 \cdot 8$. Only one of twenty healthy persons tested showed migration inhibition under equal conditions. Brostoff and others (1973), who studied migration inhibition with aggregated gammaglobulin, could only show significant inhibition in $45 \%$ of the patients tested. Our previous work (Eibl, 1972) indicated that RA patients, whose lymphocytes react with antigen-antibody complexes, also react with aggregated globulin. For this reason we assume that the higher percentage of positive results in our studies is due to the more sensitive experimental system we used. Brostoff used buffy coat cells, a mixture of granulocytes, monocytes, and lymphocytes. We used isolated mononuclear cells consisting of lymphocytes and monocytes, and it is likely that granulocytes not reacting in this system dilute the effect.

To differentiate whether the migration inhibition observed is caused by the reaction of T-cells or by cells involved in the production of rheumatoid factors, we tried to correlate the presence and titres of rheumatoid factors in the patient's serum with migration inhibition of his lymphocytes. No correlation was shown, suggesting that early steps of rheumatoid factor production are not of major importance in the migration inhibition observed. Bach and others (1970), testing lymphocyte reactivity to antigenantibody complexes by rosette technique, came to similar conclusions, In our previous studies using the rosetting system with human D-positive erythrocytes and human anti-D IgG antibody (Eibl and others, 1973), no correlation could be found with rheumatoid titres, either.

If migration inhibition has to be regarded as an in vitro correlate of delayed hypersensitivity, it has to be caused by soluble mediators produced by T-lymphocytes. It was, therefore, of interest to investigate whether such soluble mediators can be shown in the reaction between mononuclear cells of RA patients and antigen-antibody complexes. We preferred to use a particulate antigen, such as the red cell which can easily be separated from the MIF-containing supernate. To test the reactivity of RA lymphocytes with antigen-antibody complexes, we coated red cells with homologous IgG antibody. Lymphocytes incubated with erythrocytes 
alone served as controls. This type of control has been regarded as the most suitable one because the number of cells and metabolic conditions could be considered identical in control and experimental cultures. MIF production was shown in 16 of 20 lymphocyte preparations from RA patients, with guinea pig peritoneal macrophages as target cells. Only 2 of 20 lymphocyte preparations from healthy persons produced MIF after incubation with antigen antibody complexes. The difference between the patients and the controls was statistically highly significant. These data provide substantial evidence that mediators are produced by lymphocytes of RA patients on reaction with homologous antigenantibody complexes and that the migration inhibition observed can be regarded in most of the patients as a true reaction of delayed hypersensitivity. We could not show the production of mediators in all of the patients tested and do not want to postulate that this is the only type of reaction between mononuclear cells of RA patients and antigen-antibody complexes.

The importance of sensitized lymphocytes in RA has been suggested by several previous studies and lymphocytic infiltration of the synovia in the early stage of the disease supports this. Delayed hyper- sensitivity to synovial tissue could be shown in RA patients by skin testing (Braunsteiner, Eibl, and Fellinger, 1961) and by migration inhibition (Rothenberger and Thiele, 1971). Kinsella (1973) showed that joint fluid of RA patients induced in vitro transformation of autologous peripheral blood lymphocytes. This response could either be due to the effect of soluble mediators or to antigen-antibody complexes present in the joint fluid of RA patients.

The results in this paper support the assumption that antigen-antibody complexes can trigger the production of mediators by T-lymphocytes in RA under conditions where cells of healthy persons do not react. We think the difference observed between RA patients and controls is quantitative and might represent amplification of a physiological mechanism in rheumatic disease.

We wish to thank Professor K. Fellinger and Dr. N. Thumb (II. Medical Clinic of the University of Vienna) for allowing us to study their patients, and Dr. P. Bauer for statistical analysis of our data. The excellent technical assistance of Mrs. M. Mirickova is gratefully acknowledged. This work was supported by a research grant of the 'Fonds zur Förderung der wissenschaftlichen Arbeiten in Österreich'.

\section{References}

Aiuti, F., Lacava, V., Garofalo, J. A., D’Amelio, R., and D'Asero, C. (1973) Clin. exp. Immunol., 15, 43 (Surface markers on human lymphocytes: studies of normal subjects and of patients with primary immuno deficiencies)

Bach, J. F., Delrieu, F., and Delbarre, F. (1970) Amer. J. Med., 49, 213 (The rheumatoid rosette. A diagnostic test unifying sero positive and sero negative rheumatoid arthritis)

Braunsteiner, H., Eibl, M., AND Fellinger, K. (1961) Wien. Z. inn. Med., 42, 530 (Allergie vom verzögerten Typ gegenüber Gelenksextrakten bei Patienten mit primär chronischer polyarthritis)

Brostoff, J., Howell, A., AND RoITt, I. M. (1973) Clin. exp. Immunol., 15, 1 (Leucocyte migration inhibition with aggregated gamma globulin in patients with rheumatoid arthritis)

EIBL, M. (1971) Wien. klin. Wschr., 83, 17 (Zelluläre Immunität gegen denaturiertes IgG bei der PCP)

- (1972) Z. Immun.-Forsch., 144, 103 (Nachweis der zellulären Immunität gegen homologes und autologes, aggregiertes sowie gegen komplex gebundenes IgG bei primär chronischer Polyarthritis)

- Sitko, C., AND THUMB, N. (1973) Z. inn. Med., 54, 8 (Rosettenbildung von PCP-Lymphozyten mit homologen Antigen-Antikörper-Komplexen)

Falk, R. E., ThorSBy, E., Möller, E., AND Möller, G. (1970) Clin. exp. Immunol., 6, 445 (In vitro assay of cellmediated immunity: the inhibition of migration of sensitized human lymphocytes by HL-A antigens)

FRÖlaND, S. S., AND GAARDER, P. I. (1971) Lancet, 1, 1071 (Leucocyte-migration inhibition induced by IgG in rheumatoid arthritis)

KINSELLA, T. D. (1973) Clin. exp. Immunol., 14, 187 (Induction of autologous lymphocyte transformation by synovial fluids from patients with rheumatoid arthritis)

Ropes, M. W., Bennett, G. A., Cobb, S., Jacox, R. G., and Jessar, R. H. (1959) Ann. rheum. Dis., 18, 49 (Revision of diagnostic criteria for rheumatoid arthritis)

RothenberGer, W., AND THIELE, H. G. (1971) Lancet, 2, 372 (Leucocyte migration inhibition in rheumatoid arthritis)

SACHS, L. (1969) in 'Statistische Auswertungsmethoden'. Springer, Berlin

STEFFEN, C. (1968) in 'Allgemeine und experimentelle Immunologie und Immunopathologie sowie ihre klinische Anwendung', p. 607. Thieme, Stuttgart

THORSBY, F., AND BRATLIE, A. (1970) 'A rapid method for preparation of pure lymphocyte suspensions, in 'Histocompatibility Testing,' ed. P. I. Terasaki, p. 655. Munksgaard, Copenhagen 